\title{
Increased Cutting Conditions when Machining Heat-Resistant Steel Using Replaceable Inserts
}

Pavel Dostal ${ }^{1}$ (0000-0002-3883-6300), Marek Sadilek ${ }^{1}$ (0000-0001-6680-6865), Lukas Kusnir ${ }^{1}$ (0000-0001-7676390X), Karel Kouril2 (0000-0003-0603-8053), Robert Cep ${ }^{1}$ (0000-0001-9610-4215)

${ }^{1}$ Faculty of Mechanical Engineering, 17. listopadu 2172/15, 70800 Ostrava-Poruba, Czech Republic. E-mail: dostal.pa@email.cz; marek.sadilek@vsb.cz; lukas.kusnir@vsb.cz; robert.cep@vsb.cz

${ }^{2}$ Faculty of Mechanical Engineering, Technicka 2896/2, 61669 Brno, Czech Republic. E-mail: karel.kouril@vutbr.cz

The topic of the article is the increase of cutting conditions in the machining of heat-resistant steel using exchangeable inserts. The main part is the design of a new technology for machining one of the heatresistant materials using replaceable inserts, including a discussion of any defects and economic evaluation. The aim is to reduce production costs and contribute to the elimination of production times. These modifications of technologies have a positive effect on the overall economy of production and the use of new methods in practice. Heat-resistant steels have found application in many branches of production, especially in the aerospace industry for jet engine components. Their specific properties need a more detailed examination of the optimal conditions for their processing.

Keywords: Heat-resistant steels; machining; cutting conditions; indexable inserts; aviation

\section{Introduction}

Production in the aerospace industry includes the full range of machining methods used. This is both conventional and unconventional machining. Each of these areas has a very wide range of applicability of technological possibilities. The solved problem of the article is the machining of one of the types of parts of the third stage of the nozzle. This part is part of the jet engine used in private aircraft. The reason for the machining solution is an attempt to speed up the overall production due to the replacement of previously used inserts. The solution is to increase the cutting conditions when machining with ceramic cutting inserts. Suitable cutting conditions with economic benefits are selected. [1]

Today, a wide portfolio of engineering companies is putting pressure on production speed. Engineering companies need to speed up production to keep up and be competitive. Various tools to speed up individual processes are used. From the engineering point of view, it is an effective use of machine times, ie. so that the individual machine has as little downtime as possible. Each workplace goes through different ways of automation. Production automation includes automatic clamping of workpieces, automatic exchange of used tools and much more. Quick and efficient tool change is included to speed up individual downtimes. In order to prevent the operator from having to remove an individual tool from the machine after each blunting of the tool, VBDs are now used. These for both milling and turning are used. The use of these cutting materials not only affects the speed of tool change, but also has a financial positive. The purchase price of inserts is in the hundreds of crowns. These tools also have the great advantage that the tool body remains fixed in the machine and only these inserts are changed while maintaining the same tool geometry (taking into account the insert tolerance). Another advantage is that the holder can be used on several types of cutting inserts with the same cross section. Last but not least, inserts have the advantage that higher cutting speeds can be used. [1]

This product is mostly used in engines for passenger aircraft. The types of motors in which it is used are marked TFE731-20, TFE731-40, TFE731-60. The part is referred to as the third stage of the turbine nozzle. The primary functions of the part in the motor are non-rotating, ie: effectively set the angle of the rotor air flow, set the distance to the adjoining rotor, seal for the secondary flow (honeycomb is used). The main dimensions that must not be disturbed to ensure proper function are: flange profile, flange flatness, flange thickness, flange seal width, front diameter, perpendicularity of all faces and diameters, largest inner diameter, distance of slots (cuts) from blades (in small inner diameter, riveted honeycomb). [1]

Cutting materials are the subject of many development work. In the 90s operations that asted $100 \mathrm{mi}-$ nutes, so nowadays a minute is enough for this operation. Development of cutting materials unconditionally contributed to the production efficiency of today. There are currently cutting materials that are able to 
optimize the desired operation. Among the wide selection cutting materials, there is always at least one that material under certain conditions can machine. At first it was an HSS, the use of which was great. The evolution of time has they gradually produced harder, more durable and more adaptable cutting materials. These cutting materials are began to design so that hard and expensive cutting material was used as little as possible, therefore, replaceable inserts have been developed that can be manufactured today in any shape with any chip breaker and of any cutting material. [6]

\subsection{High speed tool steel (high alloy)}

- has up to $25 \%$ alloying elements (Cr, W, V, Mo),

- the blade does not dull even at high temperatures $=>$ allows high cutting speeds,

- they can withstand temperatures up to $600{ }^{\circ} \mathrm{C}$ at the cutting point.

\subsection{Sintered carbides (SK)}

- It is made of tungsten carbide and titanium carbide,

- the binder is cobalt,

- at the point of cutting they can withstand temperatures up to $900^{\circ} \mathrm{C}$,

- they are produced by powder metallurgy (sintering) - at high temperature and pressure the powders and the binder are compressed into the desired shape.

At present, most SK inserts are coated with high hardness and abrasion resistance. The following for coating are used: titanium carbide $\mathrm{TiC}$, titanium nitride TiN, titanium carbonitride TiCN, aluminum titanium nitride TiAlN, alumina (ceramic) $\mathrm{Al}_{2} \mathrm{O}_{3}$. For coating, two methods are used, namely the CVD chemical vapor deposition method and the PVD method physical vapor deposition. The CVD method consists in the chemical reaction of compounds in the gaseous state, which are heated to a high temperature. The PVD method takes place at low incident pressures particles. The coatings are formed by sputtering, vapor deposition and ion implantation. Inserts from SK for machining around $900^{\circ} \mathrm{C}$ are used. [6]

\subsection{Cutting ceramics}

- produced by sintering of alumina $\left(\mathrm{Al}_{2} \mathrm{O}_{3}\right)$,

- they can withstand temperatures up to $1200^{\circ} \mathrm{C}$ at the cutting point,

- CA - alumina-based oxide ceramics,
- $\quad \mathrm{CN}$ - non-oxide ceramics based on silicon nitride - CM - mixed ceramics.

Cutting ceramics is a material that does not have a metal base. These cutting materials are distinguished high hardness even at high machining temperatures, around $1200{ }^{\circ} \mathrm{C}$. Cutting ceramics has low weight, do not chemically react with machined materials and have a high blade life and they at high cutting speeds (300 $1600)$ are used. Cutting ceramics is one of the most powerful tool materials, but some of them need to be followed when using it prescribed rules. Ceramic cutting materials should not be used for unstable machining, ie. in case of unstable removal of the surface layer. Cutting ceramics should also not be use for intermittent cutting. When machining with this cutting material, the rigidity of the machine must be tool, the workpiece in the best possible ratio, so as not to cause adverse shocks that would could result in chipping of the ceramic insert edge. Cutting ceramics can be divided into two types, namely alumina $\mathrm{Al}_{2} \mathrm{O}_{3}$ and nitride ceramics $\mathrm{Si}_{3} \mathrm{~N}_{4}$.

\subsection{Cermets}

- transition between SK and cutting ceramics,

- withstand higher temperatures than SK and are less brittle than cutting ceramics.

\subsection{Superhard cutting materials}

- $\mathrm{BN}$ - Polycrystalline boron nitride,

- DP - Polycrystalline diamond.

\subsection{High thermal resistance super alloys}

Under this term is a number of different metals such as refractory based alloys iron, nickel-based refractory alloys, cobalt-based refractory alloys. These alloys were formed from metals that have been developed by metallurgists in order to improve the strengthto-weight ratio heat resistance and corrosion resistance. In connection with this development, concepts have become known superalloys and metals for spaceflight. The materials developed in this way had to meet high standards requirements for resistance to external influences. When these conditions were met, the materials became harder to machine. The properties that the new alloys have are: low thermal conductivity, which affects the cutting edge temperature during machining, the tendency to form an increase, high shear strength that requires high cutting forces during machining, therefore greater blade wear and therefore shorter service life Tools. These alloys do not lose their strength even at high temperatures. This results in exerting great pressure on the blade. It is therefore necessary to select for a suitably selected cutting edge geometry suitable pressure distribution so that the gre- 
atest heat is adequately distributed over the surface forehead to maintain the sharpness of the cutting edge of these abrasive metals. Cast and forged steels contain high amount of abrasive particles, which negatively affect our machining and therefore it is necessary reduce cutting speed. The most commonly used materials are nickel and titanium alloys. These durable materials have a long tradition in the production of aircraft engines. Refractory materials are in aviation is mainly used for the construction of aircraft engines, where very high temperatures operate together with the high pressure of the air passing through the turbine. When burning aviation fuel high temperatures develop which these materials must withstand. Nickel alloys last up to $1300^{\circ} \mathrm{C}$ (Inconel 718) while maintaining properties (permitted losses). The production of semi-finished pro ducts is mostly casting technologies. This method of production is difficult to shape because of some parts are of the so-called blade type. This casting requires the articulation of different types of cores such as for example wax. The technology of machining material with these properties is currently at a high level, but higher demands are placed on processing speed and so-called production time individual components. The specific cutting force of titanium alloys is around $1300-1400 \mathrm{~N} / \mathrm{mm}^{2}$ and hardness from 200 to $400 \mathrm{HB}$, for special refractory alloys then 2400 - $3100 \mathrm{~N} / \mathrm{mm}^{2}$, resp. 200 - $300 \mathrm{HB}$. [6,7]

\section{Machined material}

Tab. 1 Chemical composition of AiResist $319[2]$

\begin{tabular}{|l|l|}
\hline Element & $\begin{array}{l}\text { Element Percentage } \\
{[\mathbf{\%}]}\end{array}$ \\
\hline Carbon & $0.16-0.22$ \\
\hline Cobalt & $1.0 \mathrm{max}$ \\
\hline Chrome & $12.0-14.0$ \\
\hline Copper & $0.5 \mathrm{max}$ \\
\hline Iron & $0.25 \mathrm{max}$ \\
\hline Manganese & $0.25 \mathrm{max}$ \\
\hline Molybdenum & $3.8-5.2$ \\
\hline Phosphorus & $0.015 \mathrm{max}$ \\
\hline Sulphur & $0.015 \mathrm{max}$ \\
\hline Silicon & $0.5 \mathrm{max}$ \\
\hline Titan & $0.5-1.0$ \\
\hline Zircon & $0.05-0.1$ \\
\hline Niob+Tantal & $1.8-2.8$ \\
\hline
\end{tabular}

The semi-finished product for the workpiece is made by the casting method. This method is shapedemanding, because the part is the so-called blade type. Wax cores to create the required shape and position of the blades are used. The initial machining of the casting is performed on a manual lathe. By means of a special clamping jig which is designed so that the subsequently created surfaces are in the exactly required position for the future shape of the part.
These created surfaces for clamping for the $\mathrm{CNC}$ lathe and for the examined operation are used. The material is marked AiResist 319. AiResist 319 are weldable nickel-based steels, superalloys for static components for aircraft engines that are corrosion resistant and resistant to high temperatures while maintaining strength at operating temperatures up to about $980^{\circ} \mathrm{C}$. The chemical composition of AiResist 319 is shown in Table 1. [2]

\section{Overview of current machining technology}

The machine on which the investigated operation is performed is a Daewoo Puma 450A CNC LATHE with serial number PM450120. Using this machine for this operation is standard. The Puma 450A is not only used for this type of operation, so the usability is more diverse. The technical parameters of the machine are listed in Table 2.

Tab. 2 Technical parameters of the machine tool [3]

\begin{tabular}{|l|l|}
\hline Machine tool parameters \\
\hline Length & $\begin{array}{l}4900 / 6200 \mathrm{~mm} \text { with chip } \\
\text { conveyor }\end{array}$ \\
\hline Width & $\begin{array}{l}2000 / 2520 \mathrm{~mm} \text { with con- } \\
\text { trol panel }\end{array}$ \\
\hline Height & $2570 \mathrm{~mm}$ \\
\hline Weight & $9800 \mathrm{~kg}$ \\
\hline Power & $3 \times 480 \mathrm{~V} / 60 \mathrm{~Hz}$ \\
\hline Safety bus & $125 \mathrm{~A}$ \\
\hline $\begin{array}{l}\text { Main fuses of the ma- } \\
\text { chine }\end{array}$ & $100 \mathrm{~A}$. Bussmann \\
\hline Maximum current & $140 \mathrm{~A}$ \\
\hline $\begin{array}{l}\text { Machine power } \\
\text { consumption }\end{array}$ & $53 \mathrm{kVA}$ \\
\hline Main engine & $30 \mathrm{~kW}$ \\
\hline Coolant motor & $0.75 \mathrm{~kW}$ \\
\hline Lubrication motor & $0.1 \mathrm{~kW}$ \\
\hline Hydraulic motor & $2.2 \mathrm{~kW}$ \\
\hline Transformer power & $75 \mathrm{kVA}$ \\
\hline $\begin{array}{l}\text { Maximum turning } \\
\text { diameter }\end{array}$ & $630 \mathrm{~mm}$ \\
\hline Maximum flow length & $1575 \mathrm{~mm}$ \\
\hline $\begin{array}{l}\text { Number of seats in } \\
\text { the revolver head }\end{array}$ & 12 \\
\hline Maximum speed & $1500 \mathrm{rpm}$ \\
\hline Horse & Yes \\
\hline Control system & FANUC 18-T Series \\
\hline
\end{tabular}

Ceramic and sintered carbide inserts for machining are used. Ceramic inserts to remove the hard surface layer of the casting and to quickly remove additions to the necessary dimensions for the finishing sections are used. The investigated sections only concern machining with ceramic inserts. Currently, inserts from NTK with the designation RNGN 120700 T 00520 WA1 are used. This cutting ceramic is based on silicon 
nitride with good resistance to thermal shocks and shocks. Recommended cutting conditions for inserts from NTK for heat-resistant alloys with nickel base $(140$ - $475 \mathrm{HB})(<48 \mathrm{HRC})$ are:

Tab. 3 Recommended cutting speeds for nickel-based alloys for VBD from NTK [4]

\begin{tabular}{|c|c|c|c|}
\hline NTK & $\begin{array}{l}\text { Cutting } \\
\text { speed } \\
{\left[\mathrm{m}^{2} \mathrm{~min}^{-1}\right]}\end{array}$ & $\begin{array}{l}\text { Feed per } \\
\left.\text { rev.[} \mathrm{min}^{-1}\right]\end{array}$ & $\begin{array}{l}\text { Depth of } \\
\text { cut }[\mathrm{mm}]\end{array}$ \\
\hline $\begin{array}{l}\text { Roug } \\
\text { hing }\end{array}$ & $200-500$ & $0.1-0.3$ & $\begin{array}{l}\text { About. } 3 \\
\text { to } \mathrm{D}\end{array}$ \\
\hline
\end{tabular}

Workpiece turning is divided into several sections.
These sections are face turning (sections 1 and 2), inner diameter turning (section 3) and outer diameter turning (section 4).

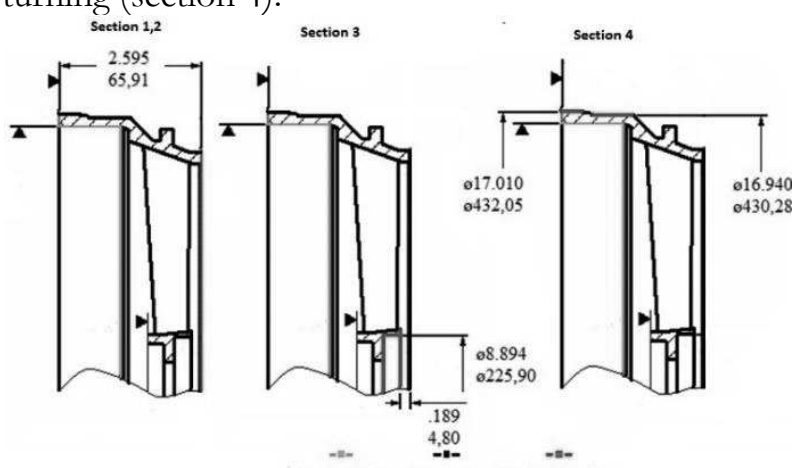

Fig. 1 Machining of sections [1]

Tab. 4 Cutting conditions for sections 1 to 4 [1]

\begin{tabular}{|c|c|c|c|c|}
\hline Name & Section 1 (NTK) & Section 2 (NTK) & Section 3 (NTK) & Section 4 (NTK) \\
\hline $\begin{array}{l}\text { Cutting speed } \\
{\left[\mathrm{m}_{\mathrm{min}}^{-1}\right]}\end{array}$ & 160 & 280 & 280 & 280 \\
\hline Feed per rev. $\left[\mathrm{min}^{-1}\right]$ & 0.127 & 0.127 & 0.15 & 0.127 \\
\hline Cutting time [min] & 3 & 2.15 & 3 & 5 \\
\hline $\begin{array}{l}\text { Cutting depth }[\mathrm{mm}] \\
\text { 1. Track }\end{array}$ & $\begin{array}{l}\text { Variable due to } \\
\text { casting tolerance }\end{array}$ & 1.3 & $\begin{array}{l}\text { Variable due to } \\
\text { casting tolerance }\end{array}$ & $\begin{array}{l}\text { Variable due to } \\
\text { casting tolerance }\end{array}$ \\
\hline $\begin{array}{l}\text { Cutting depth }[\mathrm{mm}] \\
\text { 2. Track }\end{array}$ & 1.3 & 1.0 & $\begin{array}{l}2.54 \text { to D } 0.75 \text { on } \\
\text { the forehead }\end{array}$ & 0.5 to $\mathrm{D}$ \\
\hline
\end{tabular}

When machining this surface with the T01 tool (section 1), shocks occur. These are caused by uneven sampling areas and small risers in the cutting area. The spindle load fluctuates, but is up to $20 \%$. The surface does not show

obvious mechanical damage. Particles of cutting ceramics are often chipped at the cutting edge of the insert. The service life of one cutting edge is only the cutting time of one section in the program, another possibility of use

could result in the rupture of the insert and possible mechanical damage to the surface of the machined material. An example of damage to the cutting edge after passing the section is shown in Fig. 2. [1]

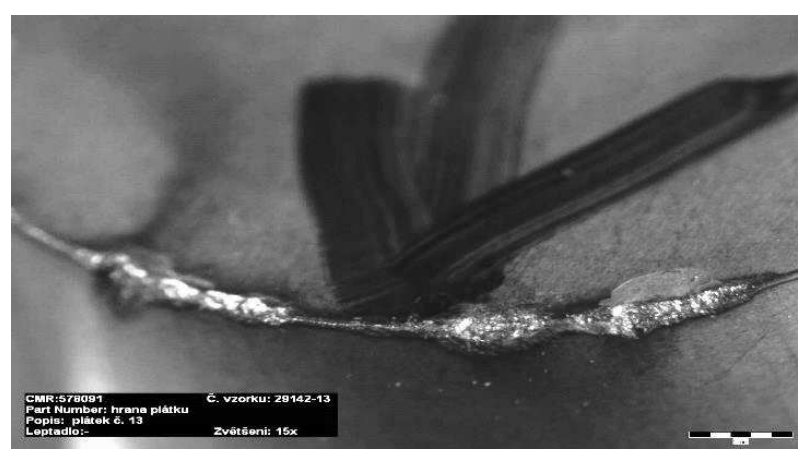

Fig. 2 Demonstration of damage to the cutting edge of the VBD from NTK to section 1 T01 [1]

When machining this surface with the T03 tool (section 2), no sharp shocks occur, the surface is already machined, and therefore the spindle load is no longer fluctuating and is also around 20\%. Machining is smooth, the surface does not show obvious mechanical damage, but often there is a slight push of the machined material under the machined face. However, this is not a negative phenomenon; excess material is removed when the dimension is completed. The service life of one cutting edge is only the cutting time of one section in the program. [1]

When machining this surface with a tool (section 3 ), shocks occur again due to the unevenness of the casting. The spindle load is fluctuating, caused by shocks, but it is up to $15 \%$. In the second tool path, machining is calmer without obvious shocks, the spindle load is no longer fluctuating and also ranges up to $15 \%$. In most cases, the cutting edge of the insert has more mechanical damage than in section 1 . The machined surface therefore has a greater surface roughness and an Archimedean spiral is more visible on the front surface. The service life of one cutting edge is only the cutting time of one section in the program. [1]

When machining this surface with the T05 tool (section 4), no shocks occur, but the cut is unstable due to the variable chip cross section. The spindle load during the first tool path fluctuates, but is up to $15 \%$. In the second tool path, of course, the cut is calmer, but due to the large machined area, the cutting edge of the insert is mechanically damaged. The damage is visible to the eye, but this does not have a significant effect on the quality of the machined surface. An example of damage to the cutting edge after section 4 
is shown in Fig. 8. The service life of one cutting edge is only the cutting time of one section in the program. [1]

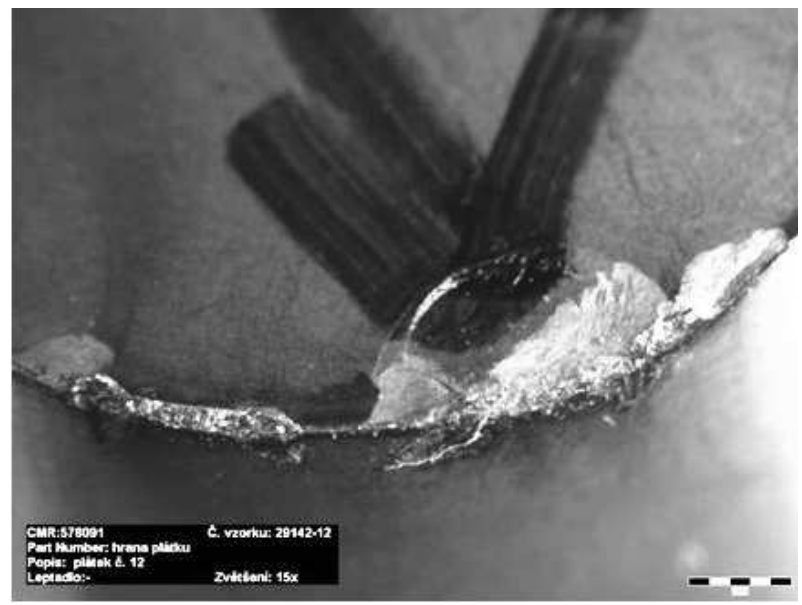

Fig. 3 Demonstration of damage to the cutting edge of the insert from NTK after section 4 T05 [1]

\section{Design of new machining technology}

The new machining technology consists of the exchange of inserts from RNGN 120700 T 00520
WA1 to RNGN 120700 E KYS25 and RNGN 1207 $00 \mathrm{~T} 01025 \mathrm{KYS} 25$ from Kennametal. KYS25 is the latest development product for machining heat-resistant steels, nickel-based steels and high-strength steels. This ceramic has a CVD coating with a silicon base with special surface treatments that significantly improve the surface proportions and performance, which can be compared with Whisker ceramics.

Tab. 5 Recommended cutting speeds for nickel-based alloys for Kennametal inserts [5]

\begin{tabular}{|l|l|l|l|}
\hline $\begin{array}{l}\text { Ken- } \\
\text { na- } \\
\text { metal }\end{array}$ & $\begin{array}{l}\text { Cutting } \\
\text { speed } \\
{\left[\text { m.min }^{-1}\right]}\end{array}$ & $\begin{array}{l}\text { Feed per } \\
\text { rev. [min }\end{array}$ & $\begin{array}{l}\text { Depth of } \\
\text { cut [mm] }\end{array}$ \\
\hline $\begin{array}{l}\text { Roug } \\
\text { hing }\end{array}$ & $200-500$ & $0.1-0.3$ & $\begin{array}{l}\text { About. 3 } \\
\text { to D }\end{array}$ \\
\hline
\end{tabular}

Turning the product with RNGN $120700 \mathrm{E}$ KYS25 is divided into the same sections as with RNGN 1207 00T 00520 WA1. These sections are face turning (sections 1 and 2), inner diameter turning (section 3) and outer diameter turning (section 4). [1]

Tab. 6 Cutting conditions for sections 1 to 4 [1]

\begin{tabular}{|l|l|l|l|l|}
\hline Name & Section 1 (NTK) & Section 2 (NTK) & Section 3 (NTK) & Section 4 (NTK) \\
\hline $\begin{array}{l}\text { Cutting speed } \\
\text { [m.min }{ }^{-1} \text { ] }\end{array}$ & 280 & 280 & 280 & 280 \\
\hline Feed per rev. [min ${ }^{-1}$ ] & 0.127 & 0.2 & 0.15 & 0.2 \\
\hline Cutting time [min] & 1.875 & 1.35 & 3 & 3.125 \\
\hline $\begin{array}{l}\text { Cutting depth [mm] } \\
\text { 1. Track }\end{array}$ & $\begin{array}{l}\text { Variable due to } \\
\text { casting tolerance }\end{array}$ & 1.3 & $\begin{array}{l}\text { Variable due to } \\
\text { casting tolerance }\end{array}$ & $\begin{array}{l}\text { Variable due to } \\
\text { casting tolerance }\end{array}$ \\
\hline $\begin{array}{l}\text { Cutting depth [mm] } \\
\text { 2. Track }\end{array}$ & 1.3 & 1.0 & $\begin{array}{l}\text { 2.54 to D } 0.75 \text { on } \\
\text { the forehead }\end{array}$ & 0.5 to D \\
\hline
\end{tabular}

When machining this surface with the T01 tool (section 1), shocks occur. These are caused by the disproportionately removed area and small impurities in the cutting area. The load on the spindle is fluctuating, but compared to the load during machining with VBD from NTK, it was half lower, ie 10\%. After the completion of the section, the cutting edge was not chipped in any way compared to the insert from the NTL, as is the case in most cases. The machined material did not show visible mechanical damage. The service life of one cutting edge is only the cutting time of one section in the program. An example of damage to the cutting edge after section 1 is shown in Fig. 4. [1]

When machining this surface with the T03 tool (section 2), no shocks occur. The spindle load is no longer fluctuating, it was also around $10 \%$. After the completion of the section, the cutting edge was slightly mechanically broken, but in comparison with the VBD from NTK it is negligible. The service life of one cutting edge is only the cutting time of one section in the program. An example of damage to the cutting edge after section 2 is shown in Fig. 5. [1]

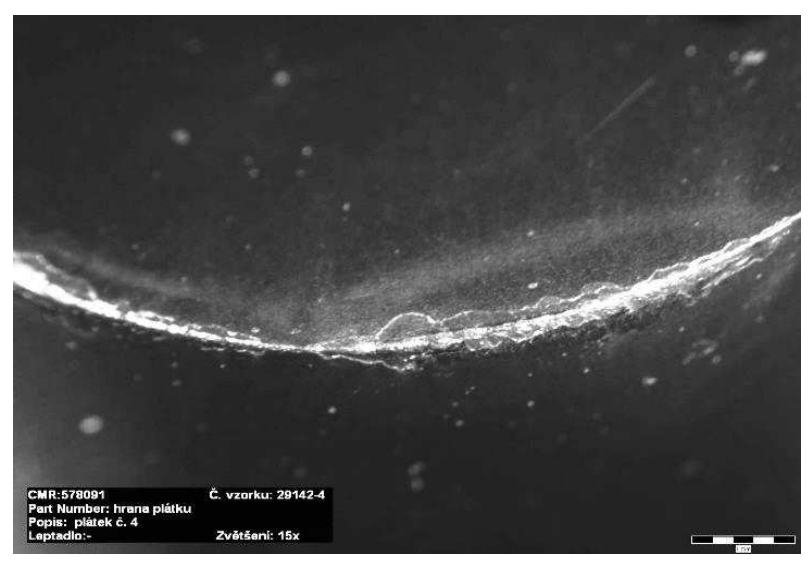

Fig. 4 Example of damage to the cutting edge of the insert by Kennametal after section 1 T01 [1] 


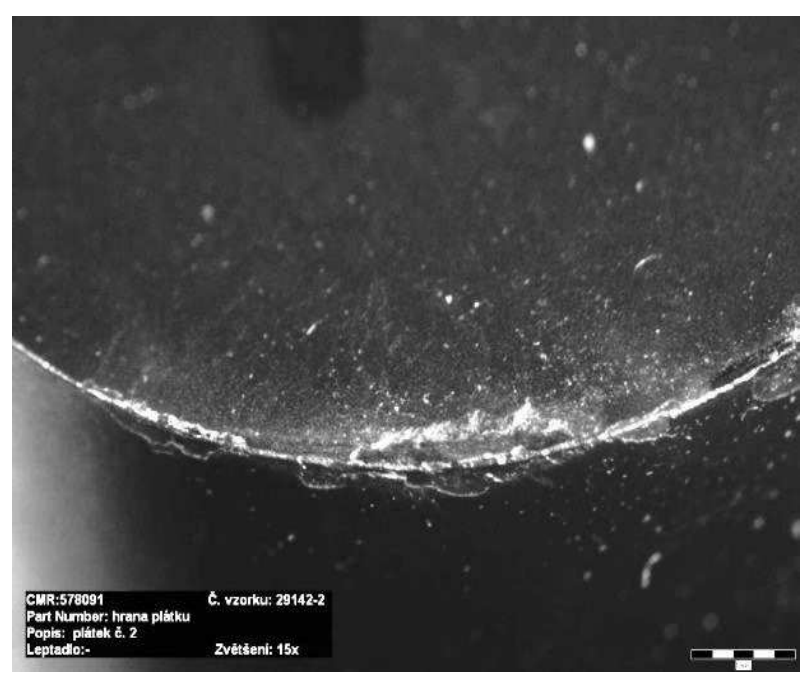

Fig. 5 Example of damage to the cutting edge of the insert from Kennametal after section 1 T03 [1]

When machining this surface with the T04 tool (section 3), shocks occur again due to the unevenness of the casting. The spindle load is fluctuating, caused by shocks, but it is up to $15 \%$. In the second tool path, machining is calmer without obvious shocks, the spindle load is no longer fluctuating and also ranges up to $15 \%$. The service life of one cutting edge is only the cutting time of one section in the program. An example of damage to the cutting edge after section 3 is shown in Fig. 6. [1]

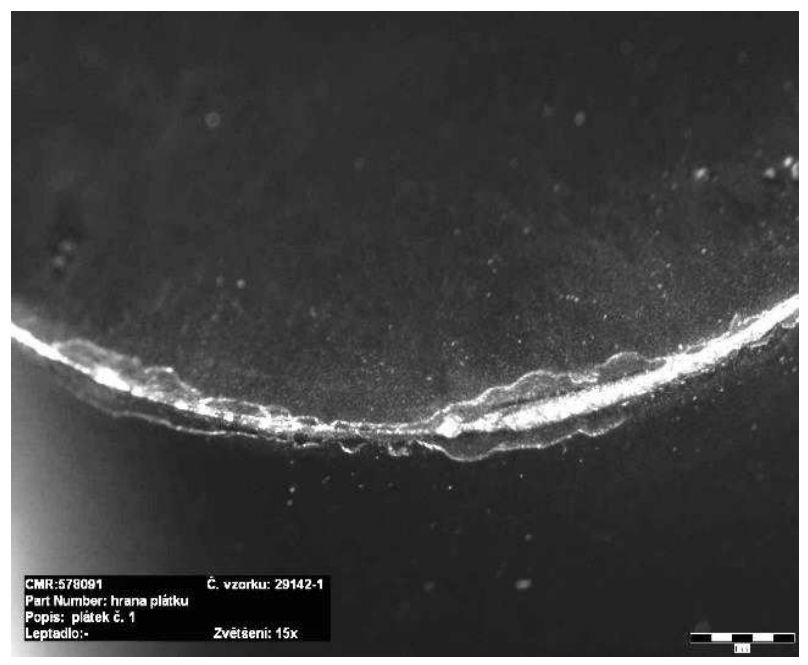

Fig. 6 Demonstration of damage to the cutting edge of the insert by Kennametal after section 3 T04 [1]

When machining this surface with the T05 tool (section 4), no shocks occur, but the cut is unstable due to the variable chip cross-section, but the cut is more stable than with NTK inserts. The spindle load is up to $10 \%$. In the second tool path, the cut is smooth, but due to the large machined surface, there is a fine mechanical damage to the cutting edge of the insert, but this does not have a significant effect on the quality of the machined surface. An example of damage to the cutting edge after section 4 is shown in Fig. 7. The service life of one cutting edge is only the cutting time of one section in the program. [1]

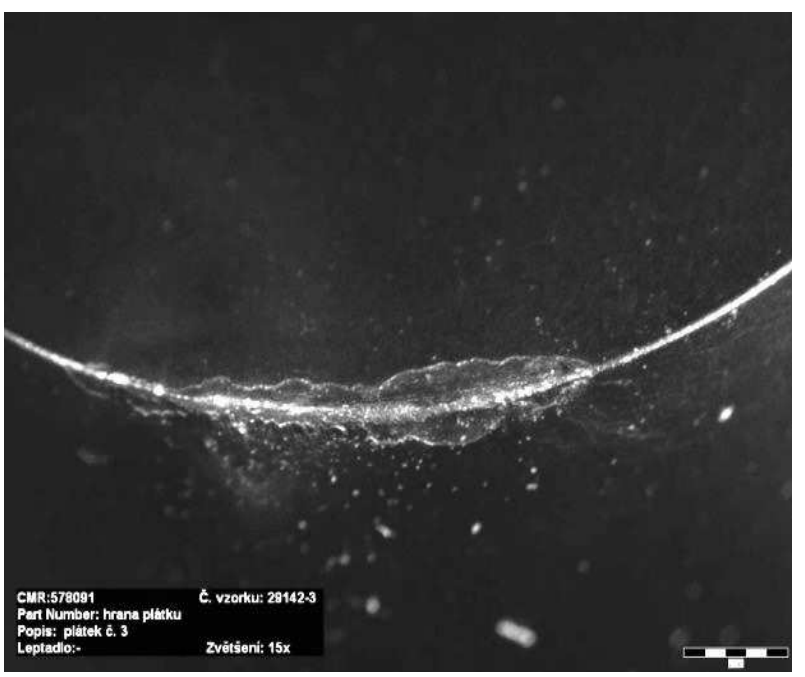

Fig. 7 Demonstration of damage to the cutting edge of the insert by Kennametal after section 4 T05 [1]

\section{Economic benefits}

Consumption of inserts is high in the company, so savings of every value are welcome. The price of the inserts from the NTK company is CZK 279. The price of the inserts from Kennametal is CZK 268, ie a saving of CZK 11 per inserts. With an average consumption of five pieces per six pieces produced, with annual orders of 215, the saving is CZK 2.315 per machining operation per year. RNGN 120700E KYS25 has the best production results depending on the speed of all cutting ceramics. The cutting conditions of these inserts increased by about $60 \%$, ie in a machine time of 7 minutes for a given operation. The annual savings are therefore CZK 26.230. In the future, the implementation of these cutting materials is planned for all operations that are performed at the workplace, the number of which is 17 . On average, five pieces of inserts per five pieces produced are consumed. If the implementation into all these operations was successful, the savings would be calculated at approx. CZK 500.000. A longer time horizon is needed for implementation into the entire production unit of the company, but after the successful introduction of high-quality and cheap inserts, the savings will go to millions of crowns per year. [1] 


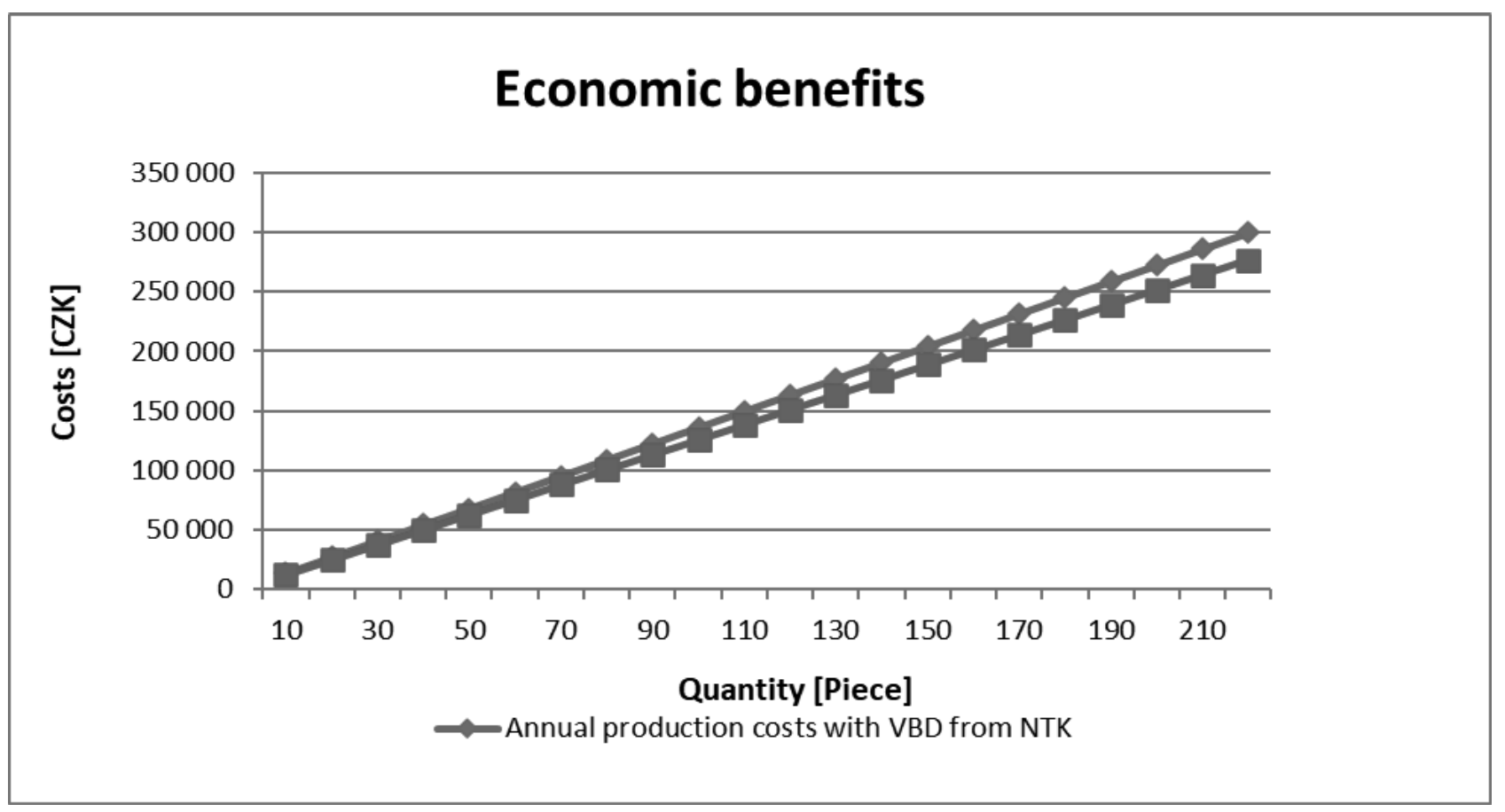

Fig. 8 Economic benefits [1]

\section{Conclusion}

Of the mentioned types of tested cutting inserts, the inserts with the designation RNGN 120700E KYS25 achieved the best results. The quality of the machined surface showed no damage, both mechanical and structural. Machining acceleration is approx. $60 \%$, ie shortening the maker time is $7 \mathrm{~min}$. for a given operation. Implementation into other production operations is planned in the future. Reducing production times means an economic benefit for every company. A slight reduction in the time of one operation will reduce production costs overall. These reductions are most pronounced in series production. Savings and efficiency help the overall economy.

\section{Acknowledgement}

Article has been done in connection with projects Students Grant Competition SP2021/100 financed by the Ministry of Education, Youth and Sports and Faculty of Mechanical Engineering VŠBTUO and by project MPO TRIO "FV40115 Development of a new series of medium-pressure valves, their manufacturing technology and testing methodology, simulating 60 years of service life" financed by the Ministry of Industry and trade, Czech Republic.

\section{References}

[1] HAVLIK, V. (2012). Increasing the Cutting Conditions during Machining Heat Resisting Steels with the Use Inserts: bachelor thesis. Ostrava: VŠB - Technical University of Ostrava, faculty of Engineering, Department of Mechanical Technology, 2012, 48 p. Thesis head: Ing. Marek Sadílek, Ph.D.

[2] Material AiResist 319 [online], [cit. 2012-05-05]. Characteristics of material AiResist 319. Available on WWW: < <ttp://books.google.com/books?id=RzMOiOE-

QoMC\&pg=PA42\&dq=material + AiResist 319 \&hl=en\&sa $=$ X\&ei $=$ FtiKTmWH4j3sga5nK3f Cw\&ved=0CDEQ6AEf3\#

[3] Deawoo puma 450a machine tool manual. Private materials and information provided by honeywell aerospace olomouc.

[4] Cutting tools from NTK catalog [online], [cit. 2012-05-16]. Catalog of cutting tools from the company NTK. Cutting speeds of various types of inserts. Available on WWW: $<$ http://www.ntkcuttingtools.com/cata$\log /$ pdf/NTK-General_Overview.pdf>

[5] Kennametal.Cz/Cd_Katalog [Online], [Cit. 2012-05-01]. Catalog Of Cutting Tools From Kennametal. Vbd Designation From Kennametal. Available On Www: Http://Www.Kennametal.Com/Images/Repositories/Pdfs/A-0902311_Aerospace_Solutions_2011.Pdf;Jsessionid=Jlqjkmwzh3j4xlaucyosfevmcqfb0iv0

[6] AB Sandvik Coromant, Machining Manual Practice Book. 1st edition Prague, 1997. 980 p. ISBN 91- 9722 99-4-6 
[7] Techtydenik.cz [online], [cit. 2012-05-16]. Cutting tools for machining selected material groups. Available on WWW: http://techtydenik.cz/reznenastroje.php?part $=12$

[8] MAREK, M., NOVÁK, M., ŠRAMHAUSER, K. (2019). The Impact of Changes in InFeed Rate on Surface Integrity after Chrome Plate Grinding by Silicon Carbide. Manufacturing Technology [online]. 2019, 19(2), 284-291 [cit. 20216-7]. ISSN 12132489. Available from: doi:10.21062/ujep/284.2019/a/12132489/MT/19/2/284
[9] SCHMITZ, T. L., SMITH, K. S. (2019). Machining dynamics: frequency response to improved productivity. Second edition. Cham: Springer, [2019]. ISBN 978-3-319-93706-9.

[10] ČUBAN, J., KOVALČÍK, J. ,2009). Comparison of coated carbide cutting tool inserts used in machining of cylinder liners made of grey cast iron. Manufacturing Technology [online]. 2009, 9(1) [cit. 2021-6-7]. ISSN 12132489. Available from: doi:10.21062/ujep/x.2009/a/12132489/MT/9/1/23

[11] HOCHENG, H., Hung-Yin TSAI, ed. (2013). Advanced analysis of nontraditional machining. New York: Springer, c2013. ISBN 978-1-4614-40536. 